\title{
Short-term and long-term effects of lay groups on weight reduction
}

\author{
ANDERS GRIMSMO，GRO HELGESEN，CHRISTIAN BORCHGREVINK
}

\begin{abstract}
Three groups participated in a slimming programme run by lay people. The course lasted eight weeks, and the average weight loss was about $7 \mathrm{~kg}$ both in a small wellcontrolled study of 33 women and in a much larger one comprising over 10000 people. Both studies were prospective. The long-term effect was studied in a random sample of about 1000 people. After four years $30-35 \%$ of the participants had kept the initial weight loss or were still reducing their weight, and only $15 \%$ had regained all the lost weight or more. That this result was better than usual may be because the programme operated through small groups of eight to 12 members run by the obese people themselves. The "slim-club hostesses" had all been obese and had succeeded in losing weight in the same programme. Group pressure and competition may also be important. Finally, the programme tried to change life styles, encouraging more exercise and reduced consumption of alcohol. The combination of scientific methods (behaviour therapy) and lay work may provide a clue for solving obesity and other serious health problems.
\end{abstract}

\section{Introduction}

Obesity is a growing health problem. Although only severe obesity is related to excess mortality, ${ }^{1}$ increase in morbidity

This study was supported by the Norwegian Association of Life Insurance Companies.

Institute for General Practice, University of Oslo, Oslo 2, Norway ANDERS GRIMSMO, CAND MED, research fellow

GRO HELGESEN, CAND PHARM, research fellow, pharmacist

CHRISTIAN BORCHGREVINK, MD, professor of general practice seems to affect people with only $25 \%$ overweight. ${ }^{2}$ Serious diseases such as diabetes, hypertension, gall stones, and psychiatric disturbances are among the most common complications accompanying obesity. The treatment of obesity by doctors has largely failed. ${ }^{3}$ In Norway, as in several other countries, self-help organisations for weight control have recently sprung up. We describe the function and the results of one such organisation (Grete Roede Slim-Clubs).

\section{Subjects and methods}

During a five-year period self-help organisations for weight control have grown into a nationwide movement. Altogether 80000 people have participated. They work in small groups, usually from eight to 12 members, meeting once a week for eight weeks, and monitoring body weight each time. They are given a low-calorie diet, are encouraged to do physical exercise, and are strongly advised against alcohol. The cost of the course, 350 Norw kroner, is paid in advance. The groups are led by non-professionals, usually women who have participated in earlier courses themselves and who have succeeded in slimming. Although not formally organised, many members meet their "hostesses" once a month after the initial course as a type of continuous slimming programme. Members are recruited mainly by advertising in the local press and through the local grapevine.

Our study was carried out in three steps. Firstly, we carried out two prospective studies looking at the short-term effect of the weight reduction programme, one in a large group and the second in two small groups closely observed by one of us $(\mathrm{GH})$. Through a retrospective survey we then studied the long-term results.

Secondly, to study the short-term effect, one of us joined two groups totalling 33 participants (all women) and followed them regularly for eight weeks, interviewing each person. Follow-up interviews were conducted after three, six, and 12 months. In addition, we obtained data from all those who started the weight reduction course during the spring of 1977 , including the initial weight, weight at weekly intervals, and the end result. The data were collected by the "slim-club hostesses" and sent to us at the end of the course.

Finally, in the retrospective study of the long-term effects we carried out a $2 \%$ structured sampling of all who had participated 
over the past five years. The slim-club hostesses throughout the country were given detailed instructions about the sampling procedure. They sent us the names, addresses, ages, heights, and weight results of 1114 selected participants at the beginning and at the end of the course. All were sent a letter and questionnaire asking their present weight.

\section{Results}

Table I givcs the results of weight reduction in the small group of 33 women who were closely followed by one of us. The average weight loss of $6.5 \mathrm{~kg}$ (range $3-10 \mathrm{~kg}$ ) at the end of the course was followed by a further decrease of $1.2 \mathrm{~kg}$ after three months. The weight at six months was still lower than at the end of the course, but after one year there was an average gain of $1 \mathrm{~kg}$ compared with the weight at the end of the course. There was still, however, a weight reduction of $5.5 \mathrm{~kg}$ compared with the starting point.

TABLE I-Short-term results and one year follow-up after an eight-week-long slimming-course (33 participants)

\begin{tabular}{|c|c|c|c|c|c|}
\hline & \multicolumn{2}{|c|}{ At the course } & \multicolumn{3}{|c|}{ Observation time } \\
\hline & $\begin{array}{l}\text { Weight } \\
\text { at start }\end{array}$ & $\begin{array}{l}\text { Weight } \\
\text { at end }\end{array}$ & $\begin{array}{c}3 \\
\text { months }\end{array}$ & $\begin{array}{c}6 \\
\text { months }\end{array}$ & $\begin{array}{c}12 \\
\text { months }\end{array}$ \\
\hline $\begin{array}{l}\text { Mean weight }(\mathrm{kg}) \\
\text { Minimum } / \text { maximum weight }(\mathrm{kg}) \\
\text { Standard deviation }\end{array}$ & $\begin{array}{c}72 \cdot 9 \\
57 / 89 \\
7 \cdot 4\end{array}$ & $\begin{array}{c}66 \cdot 4 \\
53 / 81 \\
6 \cdot 7\end{array}$ & $\begin{array}{c}65 \cdot 2 \\
53 / 82 \\
6 \cdot 3\end{array}$ & $\begin{array}{c}66 \cdot 0 \\
51 / 86 \\
7 \cdot 6\end{array}$ & $\begin{array}{c}67 \cdot 4 \\
53 / 84 \\
7 \cdot 4\end{array}$ \\
\hline
\end{tabular}

Group I-Those who had regained all or even more of the weight lost during the initial course. After one year $2.6 \%$ belonged to this group: this increased to about $15 \%$ after three to four years.

Group II-Those who had regained some, but not all, of the weight lost during the course. After one year about one-third belonged to this group, and the figure increased to about half at the end of three to four years.

Group III-Those who had either maintained the reduced weight at the end of the course or were still losing weight. After one year twothirds belonged to this group, but the figure was reduced to $35 \%$ at the end of three to four years, which is still a remarkably high proportion. Even if the $15 \%$ who did not answer our questionnaire had regained all their weight the percentage belonging to group III would still be as high as 30 .

\section{Discussion}

In collecting the data we had to rely heavily on collaboration with the slim-club hostesses. It would naturally be in their interest to obtain positive results, but in the methods used we have tried to eliminate this possible bias. In the large prospective short-term study we collected results from all participants without sampling. A record for each participant, including the initial weight, the weekly weight measurement, and the end result, was written in by the hostesses, but fully controlled by the participants themselves. Obtaining the same result both in the large and the small, carefully controlled, short-term study also strengthens the reliability. In the retrospective long-term

TABLE II-Long-term results of weight reduction in an eight-week-long course

\begin{tabular}{|c|c|c|c|c|c|c|c|}
\hline & \multicolumn{2}{|c|}{ At the course } & \multicolumn{5}{|c|}{ Observation period (years) } \\
\hline & $\begin{array}{l}\text { Weight } \\
\text { at start }\end{array}$ & $\begin{array}{l}\text { Weight } \\
\text { at end }\end{array}$ & 1 & $1-2$ & $2-3$ & $3-4$ & $4-5$ \\
\hline $\begin{array}{l}\text { Mean weight }(\mathrm{kg}) \\
\text { Mean weight (") of initial weight) } \\
\text { Minimum/maximum weight (kg) } \\
\text { Standard deviation } \\
\text { No of people observed }\end{array}$ & $\begin{array}{l}79 \cdot 5 \\
55 / 146 \\
13 \cdot 0\end{array}$ & $\begin{array}{c}70 \cdot 0 \\
88 \cdot 4 \\
50 / 118 \\
10 \cdot 5 \\
4\end{array}$ & $\begin{array}{c}69 \cdot 8 \\
87 \cdot 8 \\
53 / 114 \\
11 \cdot 3 \\
306\end{array}$ & $\begin{array}{c}69 \cdot 5 \\
88 \cdot 9 \\
48 / 120 \\
11 \cdot 0 \\
245\end{array}$ & $\begin{array}{l}71 \cdot 3 \\
90 \cdot 8 \\
50 / 110 \\
10 \cdot 2 \\
206\end{array}$ & $\begin{array}{c}72 \cdot 1 \\
90 \cdot 5 \\
49 / 115 \\
11 \cdot 5 \\
169\end{array}$ & $\begin{array}{c}75 \cdot 4 \\
93 \cdot 6 \\
64 / 95 \\
10 \cdot 0 \\
8\end{array}$ \\
\hline
\end{tabular}

In the larger prospective study of short-term effects 11410 people started the course and $10650(93.3 \%)$ completed it, indicating that the programme was obviously well accepted. The average weight reduction for those who completed the course was $6.9 \mathrm{~kg}$. Including the $6.7 \%$ who dropped out, the average weight loss was $6.4 \mathrm{~kg}$.

In the long-term study 1114 people were sent a questionnaire; a reminder was sent to those who did not reply within two to three weeks. Altogether $948(85.1 \%)$ answered, which we consider most satisfactory. There were $95.5 \%$ women and $4.5 \%$ men, the average age was 38.5 years.

Table II gives the results. As the various courses during the year did not start at the same time, we have given the observation periods as one to two, two to three, or three to four years, rather than as two, three, or four years. The average weight remained fairly stable the first couple of years, but began to rise again after three to four years. At the end of the five-year period, on average, subjects had regained about half of the weight they lost during the course, but were still $5-6 \%$ below the starting point.

We may divide the participants into three groups according to the long-term results (table III).

TABLE III-Long-term results of weight reduction when divided into three groups according to success

\begin{tabular}{ccccc}
\hline \multirow{2}{*}{ Group* } & \multicolumn{4}{c}{ Observation period (years) } \\
\cline { 2 - 5 } & 1 & $1-2$ & $2-3$ & $3-4$ \\
\hline II & $2 \cdot 6 \%$ & $6 \cdot 9 \%$ & $13 \cdot 1 \%$ & $14 \cdot 8 \%$ \\
II & $31 \cdot 1 \%$ & $44.9 \%$ & $47.6 \%$ & $49.7 \%$ \\
\hline III & $66.3 \%$ & $48.2 \%$ & $39.3 \%$ & $35.5 \%$ \\
\hline Total & $100 \%$ & $100 \%$ & $100 \%$ & $100 \%$ \\
No of persons & $306 \%$ & $245 \%$ & $206 \%$ & $169 \%$ \\
\hline
\end{tabular}

*See text for explanation. study we made several spot tests and did not find any misunderstanding of the instructions sent to the hostesses. In one group of participants we did the sampling ourselves, and this group had the same results as the others. All in all, therefore, we think that the reliability was quite good.

In a study such as the present retrospective one there is always a possibility that the replies are not honest. We have not checked this, but we emphasised the importance of honesty in our letter to the participants. The questionnaires were returned anonymously to us and not through the hostess. Furthermore, the results after one year were similar in the retrospective study and in the controlled prospective study. All in all, we think that the answers were reliable.

Comparing a self-help organisation in England-TOPS (Take Off Pounds Sensibly) - and a group led by a behaviour therapist, Levitz and Stunkard" stated in 1974: "We believe this is the clearest demonstration to date of the greater effectiveness of professional over non-professional therapeutic intervention." We disagree with this conclusion for two main reasons.

Firstly, we have shown that a lay organisation can be highly effective in helping people to lose weight. Looking at the results reached during the eight-week course, they are among the best we have been able to find (table IV).

The same probably also holds true for the long-term results, but here there are fewer studies to compare with. Feinstein ${ }^{10}$ analysed 161 articles on the management of obesity and concluded that on average $1-2 \%$ of the people taking part in the weight-losing programmes maintained initial weight-loss for five years. Craddock ${ }^{8}$ surveyed 11 long-term studies and found that $1-13 \%$ maintained some weight-loss for five years. These results along with more recent findings are shown in table $\mathrm{V}$. 
Secondly, when comparing professional and non-professional treatment of obesity the number of participants should be taken into account. Participants in most studies published about professional treatment rarely exceed 100 . We have studied over 80000 people during a five-year period. It would be almost impossible for the health-care system to cope with the problem.

TABLE IV-Short-term results of weight reduction, comparing different studies

\begin{tabular}{|c|c|c|c|c|c|}
\hline Author & Year & $\begin{array}{l}\text { No of } \\
\text { subjects }\end{array}$ & $\begin{array}{c}\text { Duration } \\
\text { (weeks) }\end{array}$ & Treatment & $\begin{array}{c}\text { Average } \\
\text { weight } \\
\text { loss } \\
(\mathrm{kg})\end{array}$ \\
\hline Stunkard et al ${ }^{\mathrm{s}}$ & 1980 & 24 & 24 & Behaviour and & $15 \cdot 3$ \\
\hline $\begin{array}{l}\text { Jeffery et } a l^{6} \\
\text { Paulsen et } \text { l }^{7}\end{array}$ & $\begin{array}{l}1978 \\
1976\end{array}$ & $\begin{array}{r}108 \\
54\end{array}$ & $\begin{array}{l}20 \\
15\end{array}$ & $\begin{array}{l}\text { Behaviour } \\
\text { Behaviour and } \\
\text { diet }\end{array}$ & $\begin{array}{l}5 \cdot 8 \\
8 \cdot 4\end{array}$ \\
\hline $\begin{array}{l}\text { Craddock } \\
\text { Kingsley and Wilson" }\end{array}$ & $\begin{array}{l}1969 \\
1977\end{array}$ & $\begin{array}{l}76 \\
78\end{array}$ & $\begin{array}{l}8 \\
8\end{array}$ & $\begin{array}{l}\text { Diet } \\
\text { Behaviour and } \\
\text { diet }\end{array}$ & $\begin{array}{l}2 \cdot 7 \\
5 \cdot 0\end{array}$ \\
\hline Present study & 1977 & 10650 & 8 & $\begin{array}{l}\text { Behaviour and } \\
\text { life style }\end{array}$ & 6.9 \\
\hline
\end{tabular}

TABLE $\mathrm{V}-$ Long-term results of weight reduction, comparing different studies

\begin{tabular}{|c|c|}
\hline Author & Long-term results \\
\hline $\begin{array}{l}\text { Feinstein }{ }^{10} \\
\text { Craddock }^{*} \\
\text { Currey et al }{ }^{11} \\
\text { Johnson and Drenick } \\
\text { Hall }{ }^{13}\end{array}$ & $\begin{array}{r}1-20, \text { kept initial weight loss } 5 \text { years } \\
1-13^{\prime \prime \prime} \text { kept some weight loss } 5 \text { years } \\
30^{\circ}, \text { kept initial weight loss } 1 \text { year } \\
70^{\circ} \text {, kept some weight loss } 9 \text { years } \\
33^{\circ}, \text { kept initial weight loss } 2 \text { years }\end{array}$ \\
\hline resent study & $35 \%$ kept initial weight loss 4 years \\
\hline
\end{tabular}

The participants were in general not grossly overweight, but still they thought their weight was a problem that they wanted to do something about. In the small prospective study only about one-quarter had consulted a doctor beforehand because of obesity. We do not have corresponding figures for the two other studies.

Owing to the informal education and the wide latitude for personal initiative among the hostesses, it is not possible to give a detailed description of the actual work done during the eight weekly meetings. We have, however, tried to analyse the ingredients in the weight reduction programme.

Firstly, it is a popular movement built on self-help principles. It is made up and run by the obese individuals themselves. The hostesses have all been obese and have succeeded in losing weight in the same programme.

Secondly, they are organised in small groups. Mechanisms, such as group pressure, competition, and strengthening of selfconsciousness play an important part.

Thirdly, the programme uses different reward systems, such as collecting points. The participants have to pay for the course in advance, so they are more likely to complete the course.

Fourthly, and finally, the programme also makes efforts to change the total life style, including changes in diet, more exercise, and reduced consumption of alcohol.

These findings have strengthened the conclusion found in recent reports about methods for treating obesity. The best results, both immediately and in the long run, are reached by combining small groups, behaviour therapy, and intervention into diets and life styles. The study also indicates that combining scientific methods with lay work might provide a clue for solving serious health problems.

\section{References}

${ }^{1}$ Garrow JS. Weight penalties. Br Med F 1979;ii:1171-2.

2 James WPT. The prevalence and risks of obesity. In: Why obesity? Näringsforskning 1978;22,suppl 15:15-26.

${ }^{3}$ Karlsson Y, Halberg DK, Pelkonen R, et al. Discussing obesity. Nordisk Medicin 1975;90:145-53.

${ }^{4}$ Levitz LS, Stunkard AJ. A therapeutic coalition for obesity; behavior modification and patient self help. Am $\mathcal{F}$ Psychiatry 1974;131:432-7.

${ }^{5}$ Stunkard AJ, Craighhead LW, O'Brian R. Controlled trial of behavior therapy, pharmacotherapy, and their combination in the treatment of obesity. Lancet 1980;ii:1045-7.

${ }^{6}$ Jeffery RW, Vender M, Wing RR. Weight loss and behavior change one year after behavioral treatment of obesity. $\mathcal{F}$ Consult Clin Psychol $1978 ; 46: 368-9$.

${ }^{7}$ Paulsen BK, Lutz RN, McReynolds WT, Kohrs MB. Behavior therapy for weight control: long term results of two programs with nutritionists as therapists. Am 7 Clin Nutr 1976;29:880-8.

${ }^{8}$ Craddock D. Obesity and its management. 2nd ed. Edinburgh: Churchill Livingstone, 1969.

${ }^{9}$ Kingsley RG, Wilson GT. Behavior therapy for obesity: a comparative investigation of long-term efficacy. $\mathcal{F}$ Consult Clin Psychol 1977;45: 288-98.

10 Feinstein AR. The treatment of obesity; an analysis of methods, results and factors which influence success. $\mathcal{F}$ Chron Dis 1960;11:349-92.

11 Currey H, Malcolm R, Riddle E, Schachte M. Behavioral treatment of obesity. Limitations and results with the chronically obese. $\mathcal{F} A M A$ $1977 ; 237: 2829-31$.

12 Johnson D, Drenick EJ. Therapeutic fasting in morbid obesity. Arch Intern Med 1977;137:1381-2

${ }^{13}$ Hall SM. Behavioral treatment of obesity; a two-year follow-up. Behav Res Ther $1973 ; 11: 647-8$.

(Accepted 31 fuly 1981)

\section{MATERIA NON MEDICA}

\section{Autumnal spores}

As there are around 3000 species of fungi of significant size which grow in Britain, any additional and simple method of identification is valuable. All too frequently close inspection of the cap, stalk, and gills, together with a nibble to determine taste, fail to permit a precise diagnosis to be made. When this occurs help can come from the spores, of which many millions originate from each fruiting body. The first thing to do is to prepare a spore print, which often proves to be unexpectedly beautiful, both in colour and geometric design. To make a print place the detached fungal cap on a piece of paper, cover it with a jam jar, and leave it undisturbed overnight. If a white print is expected then, obviously, it is better to use coloured rather than white paper.

But spore colour is not necessarily identical to that of the gills. The spore drop from the white gills of the oyster mushroom, for instance, is a delightful pale lilac. Again, the yellow-brown cap and gills of the dreaded honey fungus produce white or cream spores: the white radial design is quite fascinating, as is the pure white print of the beech cap or porcelain fungus. In the case of the porcelain fungus, however, the whiteness of the spore composition does agree with the shading of the gills and cap. Other fungal species give prints which are pink, brown, purple, or, perhaps most distinctive, black. Indeed, it is easy to get an effective black pattern from the ink-cap type of fungus, when sufficiently ripe, after only a brief space of time. Of course, not all capped fungi have radiating gills. The boletus group, for example, produce their spores in vertical tubes which open to the underside by pores; hence quite different spore pictures result.

Fungal spores are characterised by different shapes and appearances, as seen under the high power of the microscope; they may be elliptical, ovoid, lanceolate, spherical, fusiform, polygonal, or even sausage shaped. Certain fungal genera, moreover, have spores which are warty or spined, and some species show the projections connected by lines. So, if puzzled over fungal identity, spore prints, colour, and microscopic appearances are often helpful as well as revealing aesthetically attractive features. While observing the prickly, hedgehog-like spores of a puffball under magnification, one is certainly glad that one's student microscope has remained in working order.PHILIP RADFORD, Taunton, Somerset. 